\title{
Model of Customer Lifetime Value with Two Customer and a Former Customer State
}

\author{
$1^{\text {st }}$ Dony Permana \\ Study Programme in Statistics \\ Universitas Negeri Padang \\ Padang, Indonesia \\ donypermana@fmipa.unp.ac.id
}

\author{
$2^{\text {nd }}$ Syafriandi \\ Study Programme in Statistics \\ Universitas Negeri Padang \\ Padang, Indonesia \\ syafriandi@fmipa.unp.ac.id
}

\author{
$3^{\text {rd }}$ Nonong Amalita \\ Study Programme in Statistics \\ Universitas Negeri Padang \\ Padang, Indonesia \\ nonong@fmipa.unp.ac.id
}

\begin{abstract}
A model of Customer Lifetime Value can be designed by a stochastic process of Markov Chain. In the model, there are several states that must be passed by a customer. Every two states have a transition probability as a representation of state moving probability by a customer. Transition from a state to another state is assumed to fill Markov chain. In previous research, the model only has one customer state and some former customer states. Here, the model is built by two customer states and a former customer state. In real conditions, many companies are found to have more than one product variant for one type of goods/services. Typically variant differences are based on differences in taste, quality, volume/mass or services. Each variant usually has its own customer. But do not rule out that a customer can buy the product by alternating variants. The problem is how to calculate the customer lifetime value for each product variant. The expected result is an increase the total customer lifetime value compared with the previous model.
\end{abstract}

Keywords-Customer Lifetime Value, Markov Chain, Customer, Former Customer, Transition Probability

\section{INTRODUCTION}

At this time, a company often releases similar products for human needs in several variants. Usually differences in variants are based on taste, volume / mass, quality of product or service. For example BBM products in Indonesia for gasoline, Pertamina sells premium(has octane 88), Pertalite(octane 90), Pertamax(octane 92), pertamax plus(octane 92), and pertamax turbo(octane 98). The octane difference make affects to quality of fuel, certainly causes a difference in prices for each variant. The higher octane value, make the better quality of the gasoline and make more expensive the price. Examples of other products are baby / child milk products that have a variant in the net mass. Generally milk products are sold in several packages. For example packaging 1000 grams, 500 grams and 250 grams. The greater its mass has the more expensive price. There are also product variants that cost almost the same but are distinguished in taste, smell, color, shape, and others. For example soap products, food and beverage packaging, and others.

Variation differences also occur in service production. For example public transport services such as buses, trains, planes and ships. These services usually have two variants, namely economic and executive, with the difference lies in the comfort side. Of course the executive variant has a price that is more expensive than the economic variant because it offers more comfort. There are also courier or cargo services such as a post that offers two variants, namely ordinary and express, with different lengths of delivery. Express variants are more expensive than ordinary variants, because its delivery times are faster than ordinary. For insurance services, variants are made very diverse depending on the benefits that have implications for the premium price. Better benefits certainly come from more expensive premiums. While in health services, variants are distinguished in terms of the quality of service and medicine. More expensive services result in better viewing and medication. In addition there are many other service products offered by the same company but have different service variants and prices.

Each variant of the item or service has its own loyal customer group and regularly buys the product variant every time period. There are also groups of customers who often change variants. Changes in the customer's interest in the product variants purchased depend on various reasons. For example financial reasons, satisfaction or disappointment of the previous product variants, needs, influence of other consumers, or a promotional program offered by a product variant.

While the unavailability of product variants at the place of sale of products when consumers buy the product is considered not the reason for changes in customer interest. This means that each product variant is assumed to always be available at every place of sale whenever consumers need it. So that changes in customer interest are purely due to his interest in the product variant.

A consumer is called a customer for a product variant if he remains loyal to the variant he likes. At any given time period he or she always buys the variant. While the former customer is a consumer who previously bought a product variant then in the next time period he or she does not buy the product again. This means that he or she is likely to have changed the product brand. There is also a consumer who likes to change variants on the same product. One times he or she buy a one variant, next time he or she buy another variants.

The character of loyal customers, switching variants and even changing product brands will greatly affect a customer's value called the customer lifetime value or CLV. This value is inherent in a customer. Customer value is a measure of a customer's valuation from the producer side [1]. The producer considers that it is very important to the customer 
value because it can be a measure of the sustainability of a product variant in the future [2].

By definition the CLV is a prediction of the profits that producers get from a customer for their relationship throughout the time from today to the future [3]. Whereas in the calculation, the CLV is a value of expectations of the company's profits from the results of transactions with a customer starting today until a long time in the future [4]. The element of probability is the probability for consumers to still transact with producers in each time period. Whereas in view of the Markov model, the CLV is the expectation value of the status of customers who conduct transactions from today to a long time in the future. The random variable element is located in customer status that has a currency unit. While the element of probability lies in the possibility of status transfer. The probability element is represented as a customer state transition matrix.

Whatever the definition and method of calculating the CLV, the value is for potential return in the future, but it is calculated in the present. So the calculation of the CLV added a factor discount that contains an element of interest rates [5]. The interest rates is based on data of Central Bank like Bank Indonesia for Indonesia country. But, in this model, the interest rates are assumed to be constant. In the next research, the interest rates may be assumed dynamically.

The high customer lifetime value in a customer is defined as high loyalty as customers and companies get a guarantee of big profits in the future. Customers with high CLV should be given higher attention by the manufacturer. The goal is that these customers do not move to other products. The company will suffer a large loss if high-CLV customers move to other product brands.

Whereas lower CLV is the customer who change brands frequently. Character of the customer like this do not need to be given more attention, but just enough within the limits of reasonableness. If he moves, the company doesn't get big losses. If he persists, the company does not get a big profit.

In this paper, for example, a product or service has two variants with different prices. Each variant has its own customer group, namely customer group 1 and customer group 2. For modeling, we call customer state 1 and customer state 2 . A customer is assumed to have a loyalty to a product variant. He also has characters that can move interests between variant 1 and variant 2 with few probability. Brand change probability are assumed to exist with small probabilities. If he changes brands, then he moves to former customer state. So that a customer has three states options. The problem is how to determine CLV from a customer who has the initial state of each state. Diagram of customer show in Figure 1.

In Figure 1, there are three states, namely customer1, customer2, and former customer [6]. An arrows from customer1 to customer1 that have weighs $r_{1}$ indicate the probability for customer transition from customer1 to customer1 again. This means that the customer is loyal. He bought the same variant product in the next time period. The probability is called a retention probability. The arrows from customer1 to customer2 or vice versa indicate that the customer is moving from variant 1 to variant 2 or vice versa. This means that the customer's interest changes from variant
1 to variant 2 or vice versa. The weight of $a_{12}$ and $a_{21}$ shows the value of its transition probability.

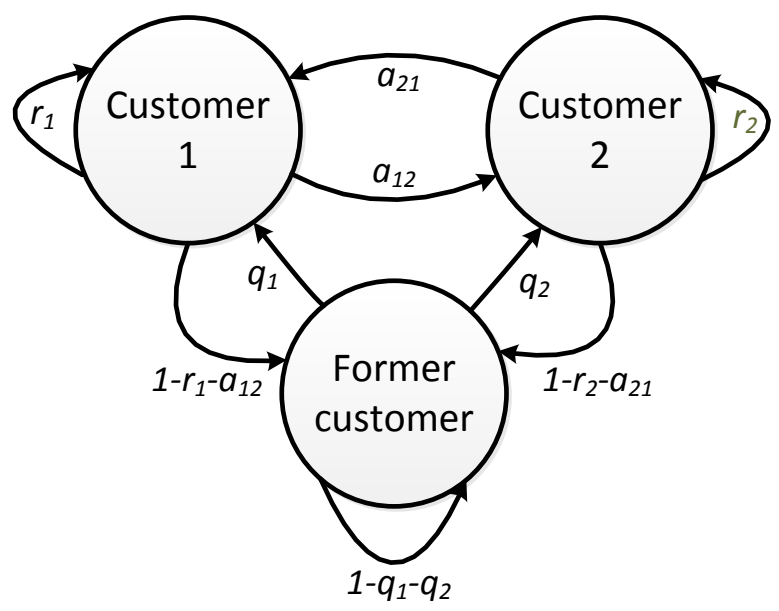

Fig 1. Transition Chart of The Model

While the arrow from customer1 to the former customer indicates that the customer has not bought the same product. This means that the customer may have changed brands. But one day the customer can return to its original status in the future. This is marked by the presence of the arrows from former customer state to customer state. The transfer of state from the former back to the customer occurs if the former is interesting again in one of the product variants and buys it. The probability of the transition have a symbol $q$ and it is called acquisition probability. If the customer back to the customer 1 from the former then be symbolled $q_{1}$ and if back to the customer 2 then be symbolled $q_{2}$. For a simulation, probability of retention is higher than probability of acquisition.

Based on the transition chart in the model in Figure 1, the following transition probability matrix is arranged as the first equation below [6].

$$
P=\left(\begin{array}{ccc}
r_{1} & a_{12} & 1-r_{1}-a_{12} \\
a_{21} & r_{2} & 1-r_{2}-a_{21} \\
q_{1} & q_{2} & 1-q_{1}-q_{2}
\end{array}\right)
$$

The size of the matrix depends on the number of states. The model has three customer states so the size of the transition probability matrix is $3 \times 3$. Symbol $r$ means the probability for retention. It's means the probability to survive the state of the customer. Symbol $a$ means the probability for inter-variant acquisition. While the symbol $q$ allows probability for acquisitions from the former customer state back to become customer state

In addition, there is a vector called vector reward as the second equation follows [6].

$\vec{R}=\left(\begin{array}{c}R_{1} \\ R_{2} \\ R_{a}\end{array}\right)=\left(\begin{array}{c}N_{1}-M_{1} \\ N_{2}-M_{2} \\ -M_{q}\end{array}\right)$

The vector represents some of cost and net contribution in every states. Size of the vector is the number of the states. 
The existence of three states are also indicating size of the vector reward which has three components. The first component $\left(R_{l}\right)$ is the value derived from the net transaction of the customer buying product variant 1 which is reduced by the marketing cost $\left(M_{l}\right)$. This cost must be expensed by the firm, thus the symbol of $M_{l}$ is negative. Net transactions are sales prices that have been reduced by variable costs but not yet reduced by marketing costs. The second component is analogous to the first component for product variant 2 . The cost here is $M_{2}$. Whereas the third component does not occur, but the company conducts marketing activities resulting in a cost of $M_{\mathrm{q}}$. While the plus sign on $N$ means that the company gets sales results. Marketing activities in the third status (excustomer) are carried out with hope the former customer is interested in buying one of the product variants. If he buys means he transitions back to one of the customer's state. But if he or she remain uninterested, he is still in the former customer state.

\section{METHODS}

In previous studies, it was found that the transition of the customer between states was assumed to follow the stochastic process of Markov chain. That is, the probability for a customer to be in a certain state is only depend on the previous state, independent of past states. This property is called Markovian. The probability for customer transitions between states are arranged into a matrix called transition probability matrix. Whereas customer status is given a unit of currency value (for example rupiah) and arranged as a vector reward.

The CLV for the Markov model in this paper is defined as follows [5],[7],

$$
\overrightarrow{C L V}=\left(\begin{array}{l}
C L V_{1} \\
C L V_{2} \\
C L V_{2}
\end{array}\right)=\sum_{t=0}^{T}\left(\frac{1}{1+i} P\right)^{t} \vec{R}
$$

P : Matrix of Transition Probability

$\mathrm{R}$ : Vector of Reward

i : Interest Rate

$\mathrm{t}:$ time

$\mathrm{T}$ : Limit time in future

For this model, because it has three states, the resulting CLV has three components as well. $C L V_{l}$ is the CLV of the customer in future $T$ if the initial state of the customer is in state 1, meaning that the customer is enjoying the product variant $1 . C L V_{2}$ is the CLV of the customer in the future $T$ if the initial state of the customer is in state 2. $C L V_{3}$ is the CLV of the customer in the future if the initial state is in state 3 . It means that the customer is not currently enjoying the product from the producer, either variant 1 or variant 2 . Maybe he or she has moved to the other brand or for some reasons. But at a previous time he was a customer of the product of variants 1 or 2 .

The next problem is to perform numerical simulations to see character of CLV results in all three components. Simulation is done by changing the value of transition probability. Interest rates are assumed constant. The reward vector is also assumed to be constant. But here, product of variant 1 is made to have a selling price twice of the product of variant 2 . This means that variant 1 has better quality than variant 2. This price difference has consequences with different marketing costs proportionally.

\section{RESULTS}

We make two kinds of simulation. The first simulation has an assumption that acquisition probability from former to customer and cost of marketing are constant. Whereas the second simulation has a assumption that the acquisition probability and the cost of marketing are dynamically. Here, both are made limit to zero. In real, if a customer didn't buy a variant of product several times, then he or she will not back to buy the variant forever. That means, the producer will lose the customer. Thus, the second simulation is similar with the real situation.

The Simulations are done to show the CLV changes in each states starting from today $(\mathrm{t}=0)$ to the time $T$ in future. Let probabilities of retention be high $\left(r_{l}=r_{2}=0.7\right)$, probabilities of transition inter variant be low $\left(a_{12}=a_{21}=0.15\right)$, and acquisition probability be lower $\left(q_{1}=q_{2}=0.1\right)$. Let net contribution for variant $1\left(N_{l}\right)$ is $\mathrm{Rp} 1$ rupiah whereas for variant $2(\mathrm{~N} 2)$ is Rp. 2 rupiahs. Let costs of marketing $\left(M_{1}, M_{2}\right)$ are $15 \%$ from each of the net contribution and M3 be average of $M_{1}$ and $M_{2}$. Let interest rate be constant in $10 \%$ annual. If $T$ is moving from zero to infinity, then the equation (3) will calculate CLV any time the $T$. Based on equation (1), here is transition probability matrix.

$$
P=\left(\begin{array}{ccc}
0.7 & 0.15 & 0.15 \\
0.15 & 0.7 & 0.15 \\
0.1 & 0.1 & 0.8
\end{array}\right)
$$

For the first simulation the parameters $q_{1}, q_{2}$, and $M_{q}$ are constant in any time $t$. Here is three plots of CLV.

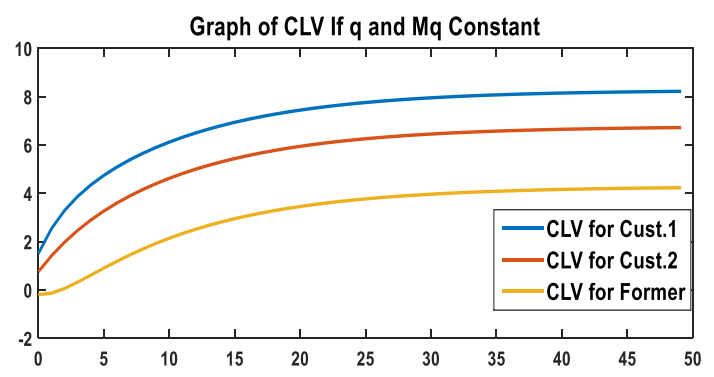

Fig 2. Dynamically of CLV of the three states along time $t$ in simulation 1

In Figure 2 it can be seen that the three CLV components increase over time. But at times in the future it tends to be constant. The first CLV component is higher because the variant price is indeed higher. The third component CLV is ultimately positive from the negative value at the beginning. This is because there is an probability for him to move to one product variant. This means that even though the chances of him returning are small but the former customer still has the potential to bring profit in the future.

Now, let $q_{1}, q_{2}, M_{3}$ be have limit to zero. Let we calculate CLV in the second simulation and here is the plots. 


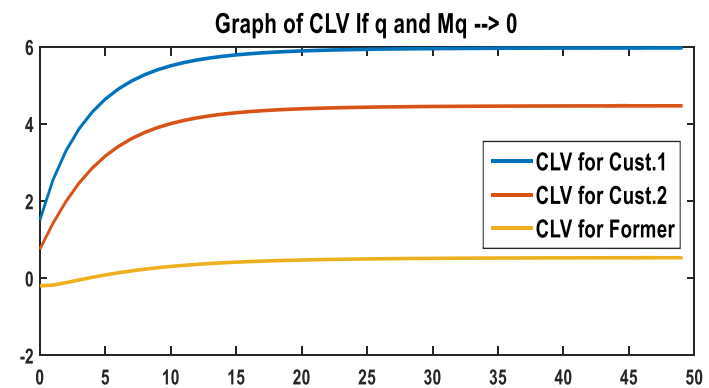

Fig 3. Dynamically of CLV of the three states along time $t$ in simulation 2

Figure 3 shows that if the former customer is a state absorbant, then its CLV will be constant zero. While CLV for the other two components is positive. Both CLVs rise and stabilize faster than the first simulation. But the stable number is smaller than the first simulation. This is because in the first simulation the former customer always has the probability to re-buy the product variant. Whereas in the second simulation, the former probability returned to be smaller so it was considered impossible to buy back the product variants offered. This means that here, the producer will lose his former customer.

\section{CONCLUSIONS}

Base on two simulations, we can have the conclusions.

1. CLV for Customer 1 is higher than CLV for Customer 2

2. In the some of period in future, CLVs tend to stable

3. We can make two cases : (1) $q$ and $M_{q}$ constant

$$
\text { (2) } q \text { and } M_{q} \rightarrow 0
$$

4. Model in case (2) is faster stable than case (1)
5. CLV for Former in model case (2) is not valuable

6. Model case (2) is more rational than case (1)

\section{REFERENCES}

1. Berger P.D. and Nasr N.I. Customer Lifetime Value : Marketing Models and Applications, Journal of Interactive Marketing12(1), 1998, p17-29

2. Blattberg, R. C., Malthose, E. C., dan Neslin, S. A. (2009). Customer Lifetime Value: Empirical Generalizations and Some Conceptual Questions. Journal of Interactive Marketing (23), 157-168.

3. Gupta, S., Hanssens, D., Hardie, B., Kahn, W., Kumar, V., Lin, N., dan Sriram, N. (2006). Modelling Customer Lifetime Value. Journal of Service Research, 9(2), 139-155

4. Permana,D., Pasaribu,U.S., Indratno,S.W., Suprayogi. (2015) : The Probability of First-time and Estimation of the Customer Lifetime Value in Health Insurance Data Using Markov Chain Model, International Journal of Applied Mathematics and Statistics, 53(3), p.174-18.

5. Pfeifer, P.E., and Caraway, R.L., 2000, Modeling Customer Relationships as Markov Chains, Journal of Interactive Marketing, 14(2), Spring, p.43-55

6. Permana D., Pasaribu U.S., Indratno S.W.,Suprayogi, (2017): Classifikation of Customer Lifetime Value Models using Markov Chain, IOP Conf. Series: Journal of Physics 893(012026),p1-6

7. Permana D., Pasaribu U.S., Indratno S.W., (2014), Analysis Study Of Behavior and Determination of Customer Lifetime Value (CLV) Using Markov Chain Model, AIP Conference. Proceedings,1589, p.456-459 